\title{
Marine Invertebrates as Bioindicators of Heavy Metal Pollution
}

\author{
Roberto Chiarelli, Maria Carmela Roccheri \\ Dipartimento di Scienze e Tecnologie Biologiche Chimiche e Farmaceutiche (STEBICEF), Università di Palermo, \\ Palermo, Italy \\ Email: robertochiarelli82@libero.it, maria.roccheri@unipa.it
}

Received 22 October 2014; revised 21 November 2014; accepted 8 December 2014

Copyright (C) 2014 by authors and Scientific Research Publishing Inc.

This work is licensed under the Creative Commons Attribution International License (CC BY). http://creativecommons.org/licenses/by/4.0/

(c) (i) Open Access

\begin{abstract}
Atmosphere, earth and water compose the environment. The presence of heavy metals in the environment has grown because of their large employment in some industrial and agricultural activities. Although these metals are terrestrial products, they flow into the sea through effluents and sewage or are directly discharged from industries placed on the seawater front. It should be considered that metals concentrations vary widely according to different seawater latitudes and depths and can be strongly influenced by fresh water discharges from heavily polluted rivers. In this review recent studies on heavy metal pollution in marine ecosystems and their organisms will be presented. Metal speciation, bioaccumulation in biota, as well as abiotic and biotic factors affecting their bioavailability will be reviewed. Moreover, the use of bioindicator organisms for the biomonitoring of heavy metal toxicity and their ecological effects will be defined. Many marine invertebrate species fulfill the following criteria: Sensitivity to a wide range of chemicals (especially to heavy metals), cost-effectiveness for repeatable tests, readily interpretable biological consequences of pollution. Among the most important marine invertebrates used as bioindicators, the sea urchin embryo is one of the most suitable, especially to assess metal/heavy metal pollution.
\end{abstract}

\section{Keywords}

Pollution, Heavy Metals, Bioidicators, Marine Invertebrates, Sea Urchin Embryos

\section{Introduction}

\subsection{Heavy Metal and Marine Pollution}

The environment is composed of the atmosphere, earth and water. More than 100,000 chemicals are released into the global environment every year as a consequence of their production, use and disposal. Chemical sub- 
stances or contaminants discharged into the environment may be of natural origin (e.g., erosion, volcanism), or of anthropogenic origin (e.g., combustion of fossil fuels, leachate from landfill sites, run-off from agricultural land, mining residues). Atmospheric metal pollution is responsible for most of the dissolved $\mathrm{Cd}, \mathrm{Cu}, \mathrm{Fe}, \mathrm{Zn}, \mathrm{Ni}$ and As in the oceans. The presence in the environment of heavy metals has grown because of its large employment in some industrial and agricultural activities.

The term heavy metal refers to any metallic chemical element that has a relatively high density and is toxic or poisonous at low concentrations in plants, animals and humans [1]. Approximately 30 metals and metalloids are potentially toxic to humans. These elements affect cells and living organisms in various ways; some heavy metals have essential functions and are toxic only in an overdose, whereas others are xenobiotic and highly toxic [2] [3]. Also, some metals which are essential in some organisms are not in the other in which they have a toxic effect (borderline).

Usually, metals and metalloids, relatively to living organisms, can be separated in three class: essentials, nonessentials and borderline class. Some of these are displayed in Table 1.

Heavy metals, not biodegradable and persistent in the environment for long periods, cause serious eco-toxicological problems. Furthermore, some toxic metals may mimic essential metals and thereby gain access to important molecular targets. To a small extent they enter into the organisms via food, drinking water and air and are bio-persistent pollutants that accumulate at the top of food chain [4].

Heavy metals are dangerous because they tend to bioaccumulate. The extent of bioaccumulation of metals is dependent on the total amount, the bioavailability of each metal in the environmental medium and the route of uptake, storage and excretion mechanisms. Compounds accumulate in animals and in plants any time they are taken up and stored faster than they are broken down (metabolized) or excreted [5].

Living organisms naturally exposed to high metal concentrations follow various mechanisms to counter potential toxicity. To detoxify the metals, they reduce their intake, enhance their excretion and/or sequestration. Metals can be sequestered through metal binding proteins, such as metallothioneins, in cellular vesicles and granules [6]. Moreover, some compounds of heavy metals are known to be stress agents and promote different defense strategies such as the synthesis of HSPs (heat shock proteins), apoptosis and autophagy, in a dose/timedependent manner.

Although heavy metals are terrestrially produced (industrial and agricultural activities), they flow into the sea through effluents and sewage or are directly discharged on the sea waterfront. In many seas surface waters often have low discharge or renewal rates, hence pollutant contamination from industries have a high negative impact on the physico-chemical and biological quality of the water.

Information about heavy metals in marine organisms, both at the whole body and at tissue levels, mostly concerns mollusks and crustaceans, but significant evidences occur also for polychaetes, coelenterates and echinoderms. Aquatic organisms, such as mussels, can regulate internal metal levels more effectively that oysters, although both species have similar feeding preferences [7]. Certain species, as fish, polychaete and bivalve mollusks are also able to regulate the concentrations of essential metals in their tissues [8].

\subsection{Marine Invertebrates as Bioindicators}

In the sea, when evaporation exceeds the contribution of rivers, the concentration of salts and pollutants is subjected to increase, causing effects on organisms, biodiversity and human health.

Aquatic invertebrates are known to accumulate high levels of heavy metals in their tissues and yet survive in polluted environments [9] [10]. Often metals penetrate the cells via transport mechanisms normally used for other purposes and are irreversibly accumulated in cells where they interact with cellular components and mo-

\section{Table 1. Classes of metals and metalloids relatively to living organisms.}

\begin{tabular}{cc}
\hline Types of heavy metal & Heavy Metals \\
\hline Essentials & Calcium (Ca), Magnesium (Mg), Manganese (Mn), Potassium (K), Sodium (Na), Strontium (Sr), Zinc (Zn), Iron \\
(Fe), Copper (Cu) \\
$\begin{array}{c}\text { Non-essentials } \\
\text { Borderline }\end{array}$ \\
Cadmium (Cd), Mercury (Hg), Silver (Ag) Tallium (Ti), Lead (Pb) \\
Chromium (Cr), Cobalt (Co) Nickel (Ni), Arsenic (As), Vanadium (V), Tin (Sn)
\end{tabular}


lecular targets. Their toxicity has been associated with blockage of oxidative phosphorylation, glutathione depletion and inhibition of antioxidant enzymatic activity, production of ROS (reactive oxygen species), DNA damage and inhibition of relevant repair mechanisms, protein misfolding disorders [11] [12].

Invertebrates occupy a key position as intermediate consumers in the pelagic as well benthonic food chains of aquatic ecosystems. Then, aquatic organisms may represent excellent bioindicators of the marine water quality. The main purpose of monitoring the concentrations of heavy metals in biota is to determine the toxicological risk faced by marine organisms and even by humans through the ingestion of contaminated edible species.

Many studies have been carried out to assess the status of chemical pollutants in marine ecosystems using different bioindicator organisms, for evaluating possible risks on human health.

To select the proper bioindicator organisms, the chemical effects were studied on adults, but, at present, they displayed two problems: 1) high efficient excretion systems for toxicants; 2) the difficulty to carefully determine which chemical pollutant is producing the observed effect, since the organisms come in contact with several contaminants. Considering these aspects, it is essential to find bioindicators that effectively reflects the health state of the sea and accurate markers of pollution. Some macroscopic markers are not always accurate because may be influenced by numerous parameters, instead, cellular/molecular markers, seem to be more reliable because are governed by specific pathways. Although it has long been highlighted the problem of marine contaminants, scientific research needs to be further developed in order to obtain a complete profile of the chemical effects on living beings, including the molecular and the cellular aspects that are governed by specific pathways and may have a key role in the definition of environmental pollution.

Embryos and larvae of marine invertebrates seem to be a suitable indicator. At present, few studies have been designed on cellular/molecular processes in developing organisms, in order to establish a toxicological profile induced by chemical pollutants.

\section{The Effects of Heavy Metals on Marine Invertebrates}

\subsection{Mercury}

Mercury (Hg) is a heavy, silvery-white metal. There are three chemical forms of Hg: elemental (Hg without any additional atoms attached to it), organic, and inorganic. These forms are interconvertible, and all can produce systemic toxicity [13].

Hg may occur naturally in the environment or from anthropogenic sources like mining, fossil fuels combustion, incineration, emission from smelters, fungicides and catalyst activities. Most Hg is volatilized and return to the atmosphere, but the greater part of this metal introduced into the coastal sea precipitates, because of the very low solubility products of its compounds.

It also accumulates in the sediment, which represents the principal sink. Most of inorganic and organic $\mathrm{Hg}$ in aquatic environment appears to be bound to particles, colloids and high molecular weight organic matter [14]. In sediments, due to bacterial activity, inorganic $\mathrm{Hg}$ may also be converted into methylmercury, the most toxic chemical species which may cause the permanent harm to the central nervous system, such as behavioral disorders and deficiencies in the immune system and development [15]. In this form methylmercury dissolves in the water column, becoming readily bioavailable; then it bioaccumulates and biomagnifies up into marine food chains leading to elevated concentrations especially in predatory organisms. Therefore, the consumption of marine products represents a non-negligible exposure pathway to Hg and, thereby, a risk for human health.

Many studies were carried out on the toxicity of $\mathrm{Hg}$ on marine invertebrates. For example, in the clam Ruditapes philippinarum, one of the most important sentinel organisms in "Mussel Watch Program" launched in China and therefore used as a bioindicator in marine and coastal ecotoxicology; metabolomics effects were detect to analyze the toxicity induced by Hg exposure in three pedigrees [16].

High level of Hg were detect in crustacean Ligia italic, a bioindicator of Hg pollution of marine rocky coasts. In this case Hg bioaccumulation resulted in remarkable ultrastructural alterations of two cellular types in the epithelium of the hepatopancreas [17]. Sublethal effects of Hg on cellular immune and biochemical responses were determined incrustacean Scylla serrata. In particular, changes in immune-associated parameters including, total haemocyte count, lysosomal membrane stability, phenoloxidase, superoxide generation and phagocytosis were observed after exposure to different Hg concentrations [18].

The role of multidrug efflux transport in the differential accumulation of inorganic $(\mathrm{HgCl})$ and organic $\left(\mathrm{CH}_{3} \mathrm{HgCl}\right) \mathrm{Hg}$ in sea urchin (Strongylocentrotus purpuratus) embryos was examined. In particular the inhibi- 
tion of specific molecular transporters increases intracellular accumulation of inorganic Hg but had no effect on accumulation of organic Hg. Similarly, pharmacological inhibition of metal conjugating enzymes by ligands significantly increases this antimitotic potency of inorganic mercury, but had no effect on the potency of organic $\mathrm{Hg}$. These results point to a specific elimination of inorganic Hg conjugates as a cellular basis for differences in the accumulation and potency of the two major forms of $\mathrm{Hg}$ found in marine environments [19].

Another proposed bioindicator for Hg contamination and the risk to humans is the oyster Saccostrea cucullata. Results obtained in this organism, related to the toxicity induced by Hg, report that the soft tissues of oysters could be a good indicator of $\mathrm{Hg}$ in the aquatic system [20]. A proteomic approach for identifying gonad differential proteins was performed in the oyster (Crassostrea angulata) following food-chain contamination with $\mathrm{HgCl}$. Hg discharged into the environmental waters can generally be bioaccumulated, transformed and transmitted by living organisms, thus resulting in the formation of Hg-toxicity. Among the analyzed molecules (14 - 3 3 protein, GTP binding protein, arginine kinase and $71 \mathrm{kDa}$ heat shock connate protein) were considered to be suitable biomarkers of environmental Hg contamination [21].

The possibility of having suitable bioindicators of $\mathrm{Hg}$ pollution is of fundamental importance and the aforementioned organisms seem well suited for this role.

\subsection{Cadmium}

Cadmium (Cd), commonly detected in aquatic and terrestrial environment, is a heavy metal released both from natural sources and anthropogenic activities (e.g. pigments, nickel-cadmium batteries, smelting and refining of metals and many other sources). Then, the presence in the environment of this metal has increased because of its large utilization in some industrial and agricultural activities. Cd is a highly toxic environmental pollutant and potent cell poison that causes different types of damage including cell death. A pollutant of worldwide concern, in fact $\mathrm{Cd}$ has been included in the list of those chemical substances considered to be potentially dangerous at the global level. The toxicity associated to $\mathrm{Cd}$ is amplified in organisms as a consequence of the metal's long biological half-life (15 - 30 years).This metal is highly dangerous not only because it easily penetrates the cells, via transport mechanisms normally used for other purposes, but also because it is eliminated very slowly, as it is not prone to bacterial detoxification [22].

Since Cd is a non-essential metal which is not physiologically present in organisms, it is irreversibly accumulated into cells, interacting with cellular components and molecular targets. The mechanisms by which Cd interacts with cellular components are probably various, though still poorly understood. It was suggested that Cd could enter cells via divalent ion transporters, such as zinc transporters [23]. Other experimental evidences suggested that the metal crosses the plasma membrane as divalent ions, exerting an agonistic role against calcium ionic channels [24]. In addition, salinity, temperature and calcium concentration may also influence Cd toxicity [25].

Although Cd toxicity is well proved, its effects are controversial, since some authors indicated that Cd can kill cells after a prolonged exposure, while some others emphasized its carcinogenic properties both in animals and humans, even at low concentrations [26]. Numerous pathologies, as teratogenesis and carcinogenesis, due to cytotoxic concentrations of the ion, have been described both in invertebrates and in higher organisms [27].

Accumulated evidence has also shown that Cd increased not only cellular ROS levels, but also lipid peroxidation and alteration in glutathione (GSH) levels in various cell types, suggesting that Cd-induced apoptosis may be connected with oxidative stress [28]. In invertebrates it up-regulates the expression of antioxidant enzymes, metallothioneins and heat shock proteins (HSPs) and down-regulates the expression of digestive enzymes, esterases and phospholipase A2. Cd also interferes with tissue organization, immune responses and cell cycles by inducing apoptosis [29].

This metal is a contaminant that is readily accumulated by aquatic animals and can be toxic to those who live in both fresh and salt water. For many aquatic predators, Cd comes largely from food and the ease with which these animals assimilate $\mathrm{Cd}$ from their prey depends in part upon the form in which this metal is bound in prey cells. It is shown that predators assimilate Cd located in the cytosol of prey cells more readily than when Cd is associated with insoluble prey components [30]. The factors controlling metal transfer between prey and predator are important for predicting trends in metal concentrations along aquatic food chains as well as the likelihood of toxic effects on animals at upper trophic levels. Specifically, high bioconcentration of this heavy metal has been found in aqueous organisms: invertebrates, such as sponges, mollusks, crustaceans, echinoderms and ver- 
tebrates, as fish. Sponges are particularly vulnerable to waterborne metals because they are able to process large amounts of water. Significant differences in Cd levels were found among sponges collected from differently impacted sites [31]. Cd, as other heavy metals, causes changes in cell morphology and affects cell aggregation in Scopalina lophyropoda, by enhancing pseudopodia/filopodia formation which promotes cell movement [32]. There is evidence of Cd accumulation in the digestive and excretory organs of some benthic organisms. Mussel gills and digestive gland of Mytilus galloprovincialis are the two main target tissues for heavy metal accumulation, which can alter the physiology of respiration and feeding processes [33]. Very high concentrations of the metal were found in the digestive gland of a few species of Antarctic molluscs [34], suggesting again that food is the primary pathway for Cd bio-accumulation and that the digestive gland plays a major role in the subsequent storage and detoxification. High concentrations of $\mathrm{Cd}$ were found in the digestive gland and kidney of mussel Crenomytilus grayanus [35]. In the renal tissue of Antarctic bivalve Laternula elliptica the high levels of Cd and its bio-accumulation can be a probable advantage for environmental adaptation in the Antarctic marine environment [36]. Cd cations were revealed in the hepatopancreas of Mytilus edulis and body wall of echinoderms such as Asterias rubens. Also sea urchins represent a widely used experimental model to test Cd accumulation, given their high sensitivity to chemical and physical environmental changes. In addition, their peculiar position in the marine trophic chain, where pelagic larvae are part of the diet of several planctonic and benthonic organisms, increases its interest (see below).

Sea urchin is a classical model to study the effects of pollutants in embryo-larval and adult life stages. This species is considered as a suitable bioindicator to monitor the marine environment. Data on cellular/molecular defence strategies, triggered after Cd-exposure, were obtained in Paracentrotus lividus embryos (apoptosis, autophagy, expression of metallothioneins and HSPs) but a lot of markers need to be tested [37] [38].

\subsection{Arsenic}

Arsenic (As) is one of the most important global environmental pollutants and is a persistent bioaccumulative carcinogen [39]. It is a toxic metalloid that exists in two oxidative states: a trivalent form and a pentavalent form, in the form of arsenous acid $\left(\mathrm{H}_{3} \mathrm{AsO}_{3}\right)$ and its salts, and arsenic acid $\left(\mathrm{H}_{3} \mathrm{AsO}_{5}\right)$ and its salts, respectively. It is rarely found as a free element in the natural environment, but arsenic compounds occur in air, water, soil, and all living tissues. The most important anthropogenic arsenic sources are the smelting of $\mathrm{Cu}, \mathrm{Ni}, \mathrm{Pb}$ and $\mathrm{Zn}$ ores and the burning of fossil fuels in households and power plants. Another source of As contamination was the use of arsenical fungicides, insecticides, herbicides, algicides, wood preservatives, and growth stimulants for plants and animals. However, human activities contribute little to the As increase of the open ocean, but may be important in estuaries and coastal waters receiving arsenic-contaminated drainage from the land.

As is considered to be an essential oligoelement for various animals, but many arsenic compounds are highly toxic [40]. Despite their known toxicity, especially organic ones, they are integral components of nutrients of many organisms in which they may play potentially important biological roles, while their utility is still uncertain in humans (in small doses they seem to improve the activity of certain neurotransmitters in the central nervous system). Arsenic presents strong carcinogenic properties, depending on oxidation state, chemical species, cell type, concentrations and time exposure, can induce apoptosis.

As may be absorbed by ingestion, inhalation, or through permeation of skin or mucous membranes. The mechanisms of arsenic toxicity differ greatly among chemical species, although all appear to cause similar signs of poisoning.

High levels of arsenicals were found in marine organisms comprising algae, crustaceans, bivalves, fish and mammals [41]. In general, concentrations of organic arsenicals in biota, except for gastropods, were directly proportional to the total concentration of As and its distribution and bioaccumulation were strongly correlated with salinity. It was demonstrated that arsenicals are mainly localized intheintestine of mullet and marsh clam [42]. Wu and colleagues have quantified the total arsenic content in 22 species of marine organisms collected from eight cities in Shandong, China. Their results suggest that benthonic organisms, such as bivalves, having a closer relationship with sediments, can accumulate more As then pelagic ones, while fishes accumulate As eating bivalves [43]. Already in 1982, Pagano and others [44] had demonstrated the highly toxic effects of As on the development of the embryos of sea urchin Paracentrotus lividus. Gaion and colleagues [45] recently investigated the toxicological effects of two As species (arsenate and dimethyl-arsinate) on the development of these embryos. Their results demonstrate that the biological damage depends both on the different arsenic compounds 
used and on the observed larval stage. These results confirm that $P$. lividus embryos and larvae are excellent bioindicators for different contaminants.

\subsection{Chromium}

Chromium (Cr) is a lustrous, brittle, hard metal. Its color is silver-gray and it can be highly polished. It does not tarnish in air, when heated it burns and forms the green chromic oxide. Cr is unstable in oxygen, it immediately produces a thin oxide layer that is impermeable to oxygen and protects the metal below.

This metal is a highly toxic trace metal presenting various degrees of risk for coastal ecosystems. Coastal Cr pollution is due mainly to dumping untreated or poorly treated industrial residues; $\mathrm{Cr}$ is usually found in its trivalent (III) and hexavalent (VI) forms. Cr (VI) is 30 times more toxic than Cr (III) and can be mutagenic and carcinogenic [46]. Different marine invertebrates were used to study the toxicity of Cr.

For example Petrolisthes laevigatus (crab) was used in a standard toxicity bioassay (semi-static, chronic) to evaluate EDTA as a chelating agent for reducing trivalent and hexavalent Cr toxicity. In particular the survival decreased linearly with the increase of Cr concentrations and dropped significantly at $40 \mathrm{mg} / \mathrm{L} \mathrm{Cr}$ (VI) and 80 mg/L Cr (III). No significant differences were observed with Cr (III) + EDTA as compared with untreated controls. Cr (VI) toxicity was greater than of Cr (III), with low individual survival rates [47].

Others effects of sublethal, environmentally relevant concentrations of Cr (VI) was tested in the gills of Mytilus galloprovincialis. Cr (VI) increased the activities of GST (GSH-transferase), GSR (GSH-related enzymes) and total glutathione content at different exposure times and at different metal concentrations, suggesting Cr (VI) detoxication/reduction at the site of metal entry. Cr (VI) exposure also increased the activity of glycolytic enzymes, indicating modulation of carbohydrate metabolism. Significant changes in the transcription of different genes were observed. In particular, the mRNA level for the 5-HTR was increased, whereas both decreases and increases were observed for GST- $\pi$, MT10, MT20 and HSP70 mRNAs, showing sex- and concentration-related differences. The results demonstrate that Cr (VI) significantly affected functional and molecular parameters in mussel gills, and indicate that this tissue represents the major target of exposure to environmentally relevant concentrations of the metal [48].

Others in vitro effects of Cr (VI) on immune parameters of the marine bivalve Mytilus galloprovincialis were evaluated using environmentally relevant concentrations of $\mathrm{Cr}$ (VI). Hemocyte incubation with different concentrations of Cr (VI) (0.1 - 1 - $10-100 \mu \mathrm{M})$ showed a stimulation of extracellular superoxide production and nitrite accumulation. Results indicate that exposure to non-toxic concentrations of Cr (VI) can modulate functional and molecular immune parameters in this invertebrate [49].

The oxidation of DNA and lipid were analyzed in the marine mussel (Mytilus edulis) in response to exposure to $\mathrm{Cr}$ (VI). DNA strand breakage in gill cells (analyzed by the comet assay) was elevated, indicating that this heavy metal is dangerous for the genome [50].

In Nereis succinea (polychaete), experiments were performed exposing the adults to different metals, e.g. Cr (VI). The model showed that $>97 \%$ of the body burden of these metals is accumulated through ingested sediment, indicating how these aquatic animals acquire metals from the environment, predominantly from their diet [51].

Increase in total Cr (VI) tissue content and lysosomal membranes destabilization were observed in Mytilus galloprovincialis digestive gland treated with high concentration of this heavy metal $\left(100 \mu \mathrm{g} \cdot \mathrm{L}^{-1}\right)$. The results demonstrated that exposure to $\mathrm{Cr}$ (VI) at low concentration did not result in strong toxicity or oxidative stress in mussel digestive gland. On the other hand, authors suggest that low concentrations of the metal can exert pleiotropic effects on mussel physiology, from the modulation of lipid and carbohydrate metabolism, to effects on the expression of estrogen-responsive genes [52].

A suitable test organism for assessing the bioavailability of sediment-bound metals should accumulate metals (such as Cr). So, the sipunculan worm Phascolosoma arcuatum was proposed and its coelomic fluid was used for this purpose. This organism indiscriminately ingestes sediment particles and has a very low uptake rate of dissolved metals, appearing to be a good bioindicators. Since the amount of Cr was found to be similar both in the coelomic fluid and in somatic tissues, the measurement of metal concentrations in the coelomic-fluid can provide a rapid estimation of metal bioavailability in marine sediments [53].

Toxicity of different metals, in particular Cr, on early developmental stages of Ciona intestinalis was observed and a potential application in marine water quality assessment was proposed. In particular, rapid tests on 
sperm viability, effects on embryonic development and effects on attachment were proposed [54].

$\mathrm{Cr}$ is used in different industry sectors and it is very toxic for the environment; the identification of suitable bioindicators related to this heavy metal is very important to safeguard the environment and the human health.

\subsection{Thallium}

Thallium (Tl) is a non-essential, malleable and rare heavy metal that is highly toxic to plants, animals and humans and is one of the emergent pollutant. The average concentration of Tl in the Earth's crust is $490 \mu \mathrm{g} \cdot \mathrm{Kg}^{-1}$ [55].

Some minerals such as lorandite and crooksite can contain up to 60\% $\mathrm{Tl}$ [56]. Soil erosion, forest fires, and volcanic activity are the predominant means by which metals such as $\mathrm{Tl}$ are naturally mobilized into the aquatic environment [57].

Dissolved Tl can be found in two oxidation states, Tl (I) and Tl (III). Although Tl (I) is predicted to be more thermodynamically stable than $\mathrm{Tl}$ (III), photo oxidation reactions and microbial activity, combined with the formation of stable hydroxocomplexes, contribute to the persistence of Tl (III) in surface waters [58].

There is limited information available on $\mathrm{Tl}$ concentrations in marine invertebrates. Tl concentrations have been measured in only about half a dozen types of invertebrates (Crustacea: Amphipoda and Cladocera) and in an equal number of fish species (Cyprinidae, Perciformes and Salmonidae).

The ease with which elements such as $\mathrm{Tl}$ are transferred from one trophic level to the next is represented by their assimilation efficiency [57].

In Clams and Mussels data on the accumulation of $\mathrm{Tl}$ were reported. These molluscs accumulate certain trace elements from the water and may be used as indicators of pollution. In the Clam Mya arenaria and the mussel Mytilus edulis, an experimental-treatment with $\mathrm{Tl}$ was carried out. In both organisms the accumulation of this metal in their tissue was reported, indicating that $\mathrm{Tl}$ enters the body and gradually accumulates in it [58].

Other studies on the effect of $\mathrm{Tl}$ in marine invertebrates were carried out in deposit-feeding invertebrates ( $\mathrm{He}$ diste diversicolor, Arenicola marina and Scrobicularia plana). Although in smaller amounts if compared to others heavy metals, the accumulation of $\mathrm{Tl}$ in the body of these organisms was showed [59]. However, considering $\mathrm{Tl}$ is a highly toxic metal whose biogeochemical behaviour in the marine environment is poorly understood it is recommended to better study its effects on marine species and find out specific bioindicators in order to monitoring the marine environment.

\subsection{Lead}

Lead $(\mathrm{Pb})$ is a bluish-white lustrous heavy metal. If ingested, $\mathrm{Pb}$ is poisonous to animals and humans, damaging the nervous system and causing different disorders. $\mathrm{Pb}$ compounds exist mainly in two main oxidation states, +2 and $+4[60]$.

$\mathrm{Pb}$ occurs naturally in the environment. However, most $\mathrm{Pb}$ concentrations that are found in the environment are the result of human activities. The larger particles will drop to the ground immediately and pollute soils or surface waters, the smaller particles will travel long distances through air and remain in the atmosphere. Part of this $\mathrm{Pb}$ will fall back on earth when it is raining.

$\mathrm{Pb}$ accumulates in the bodies of water and soil organisms and it is a bio-persistent pollutant that accumulates at the top of the food chain. The Pb-induced toxicity to marine invertebrates varies with species and their life stage. The concentration of $\mathrm{Pb}$ (and others heavy metal) was monitored and estimated in crab and shrimp. In these species different concentrations, depending on the geographical site analyzed, were found, indicating that these organisms can be considered biomarkers of $\mathrm{Pb}$ pollution [61].

A characterization of the cytosolic distribution of $\mathrm{Pb}$ was carried out in the digestive gland of the marine mussel Mytilus galloprovincialis. $\mathrm{Pb}$ was eluted in high molecular weight biomolecule range, but in elevated cytosolic $\mathrm{Pb}$ concentrations; significant amount of $\mathrm{Pb}$ was eluted in low molecular weight biomolecules. These results report the suitability of the distribution of selected metals among different cytosolic ligands as potential indicator for metal exposure [62].

Sea urchin embryos (Paracentrotus lividus), in vitro treated with Pb, a reduction of HSP70 synthesis was observed. Metal treatment caused an irregular morphology both at gastrula and, especially, at pluteus stages [63].

Others sublethal mechanisms of $\mathrm{Pb}$ toxicity were tested in the purple sea urchin (Strongylocentrotus purpuratus) during early development. In this specie $\mathrm{Pb}$ accumulation could be greatly observed, associated with a re- 
duction of body calcium accumulation [64].

Biochemical and histological toxic effects induced by environmentally relevant $\mathrm{Pb}$ concentrations, were found in green mussel (Perna viridis). Acute and chronic toxicity tests revealed toxic effects in a dose and time dependent manner. In this study, histological and biochemical enzymes, namely, catalase, reduced glutathione, glutathione S-transferase, and lipid peroxides, were correlated with chronic values and survival endpoints of $P$. viridis after chronic exposure to $\mathrm{Pb}$. Significant differences were observed when mussels were exposed to increasing concentrations, if compared to controls. These studies suggest different potential approaches to establish the seawater quality criteria thought the use of marine organisms [65].

\section{Sea Urchin Embryos as a Suitable Marine Bioindicator}

Marine organisms are highly sensitive to several kinds of stressors, and able to activate different defense strategies. The sea urchin embryo is one of the most important marine invertebrates used as bioindicators of metal/ heavy metal pollution and an important model organism in developmental biology. Recently it has been proposed as a suitable model for eco-toxicological and environmental studies aimed at the determination of the effects of chemical pollutants in the field or in laboratory experiments [66], as it continuously faces environmental, chemical, physical and biological stressors [67].

The sea urchin has been recently introduced in the list of alternative methods proposed by the European Union Reference Laboratory for alternatives to animal testing (EURL EVCAM), for the validation of methods which reduce, refine or replace (the 3Rs rule, 86/609/CEE) the use of animals for safety testing and efficacy/potency testing of chemicals, biologicals and vaccines.

Among sea urchins, Paracentrotus lividus is a very common species in the Mediterranean Sea. The high number of gametes, its external fertilization, the high developmental synchrony and embryo transparency make the sea urchin embryo a suitable model organism for cellular and developmental biology studies.

Sea urchins are an ancient group (at least 450 million years old) of the Echinoidea Class in the Phylum Echinodermata, with hundreds of species known in the world's oceans. Since about 1880, the eggs and sperms of sea urchins have been used for the study of fertilization, the metabolic activation of development and gene regulatory mechanisms governing embryogenesis. In addition, the genome of the purple sea urchin, Strongylocentrotus purpuratus, is known; its size is $\sim 800 \mathrm{Mb}$ [68]. This permitted to explore if parts of the vertebrate toolkit are also present in invertebrate deuterostomes, allowing ascertaining a lineage-specific evolution of various molecular networks.

This marine organism is sensitive to several aquatic contaminants and adopts several defense mechanism against any environmental chemical, physical and mechanical stress, in an attempt to preserve the developmental program. The sea urchin embryo represents a suitable model system to investigate the adaptive response of cells exposed to stress during development and differentiation [69] [70].

In embryos and larvae, contrary to the view that these are the most fragile stages of life, development is stable under real-world conditions and organisms are able to face environmental alterations thanks to high levels of cellular defences already present in the egg before fertilization. Later in development, adaptive responses to the environment either buffer stress or produce alternative developmental phenotypes [71].

Pollutants of anthropogenic origin, especially heavy metals, are of considerable interest for their ability to induce the activation of defense systems or interrupt the developmental program. Among heavy metal, Cd is one of the most considered stress agent studied in the sea urchin embryo and it induces different cellular effects such as apoptosis, autophagy and the synthesis of molecules of cellular protection.

During the development of sea urchin embryos and larvae, subacute/sublethal concentrations of Cd induce, morphological abnormalities, synthesis of specific stress proteins (HSPs), increased expression of metallothioneins, apoptosis and autophagy, in a dose/time-dependent manner [66].

It is important to emphasize that in some experiments $\mathrm{Cd}$ is employed as a toxic insult and it in no way constitutes an environmental stressor. On the other hand, it has been demonstrated that long-lasting exposure to Cd concentrations, similar to those found in moderately or highly polluted seawaters, causes severe developmental delays and abnormalities, showing that even very small amounts of $\mathrm{Cd}$, if accumulated in cells, produce significant cytotoxic effects [72] [73].

Autophagy has been recently reported in sea urchin embryo $P$. lividus, both during physiological development and in response to stress [38]. Several experimental approaches have been used to detect autophagy, like: identi- 
fication of autophagolysosomes, staining with acidotropic dyes such as neutral red and acridine orange (AO); immunodetection of LC3-II (an autophagic marker) Western blot and immunofluorescence analyses.

In particular AO is a metachromatic dye, emitting green fluorescence in monomeric form, and red fluorescence in bi/oligomeric form, related to the protonation of autophagolysosomes [74].

Results obtained by in vivo AO fluorescence assay and confocal laser scanning microscopy (CLSM) demonstrated that autophagy is a molecular process present in sea urchin embryos at higher level after Cd treatment and at a basal level during physiological development. Specifically, the experiments revealed a higher level of autophagolysosomes for embryos treated for 38 hours with $100 \mu \mathrm{M} \mathrm{CdCl}_{2}$, compared with controls. Embryos treated for $38 \mathrm{~h}$, after AO vital staining, exhibited a considerable number of red dots located around nuclei (Figure 1).

The high level of autophagy a specific developmental stages seems to be critical and it canreaches high levels in some extreme cases, although it is a physiological mechanism of recycling. This indicates that autophagy is a very plastic process, essential for the survival of embryonic cells. Sea urchin embryos continuously exposed to Cd provide a suitable model to study the role of autophagy inresponses to Cd-stress [75].

Considering that embryos of this marine invertebrate exposed to $\mathrm{Cd}$ activate the autophagic process in a dosetime dependent manner and selectively in response to a given stressor, the detection of this molecular process can be an useful marker of heavy metal pollution [76].

This topic is relevant since autophagy is a mechanism of self-eating, responsible for degradation and recycling of catabolites.

\section{Conclusions}

One of the most important goals of toxicological studies is to determine whether heavy metal pollution causes adverse effects on organisms. Although concentrations of priority metals in the seawater are regularly monitored worldwide, great effort is being made towards the application of biomarkers that indicate an early response in selected target organisms that finally provide evidence of the exposure to the chemical pollutants and may indicate a toxic effect. Especially effects based on the response at molecular and cellular levels represent the earliest warning signals of an environmental disturbance. Biomonitoring of heavy metals and effect studied on natural populations of organisms must take into account the pollution-induced tolerance in the communities that are exposed to particular pollutants for a long time (several generations).

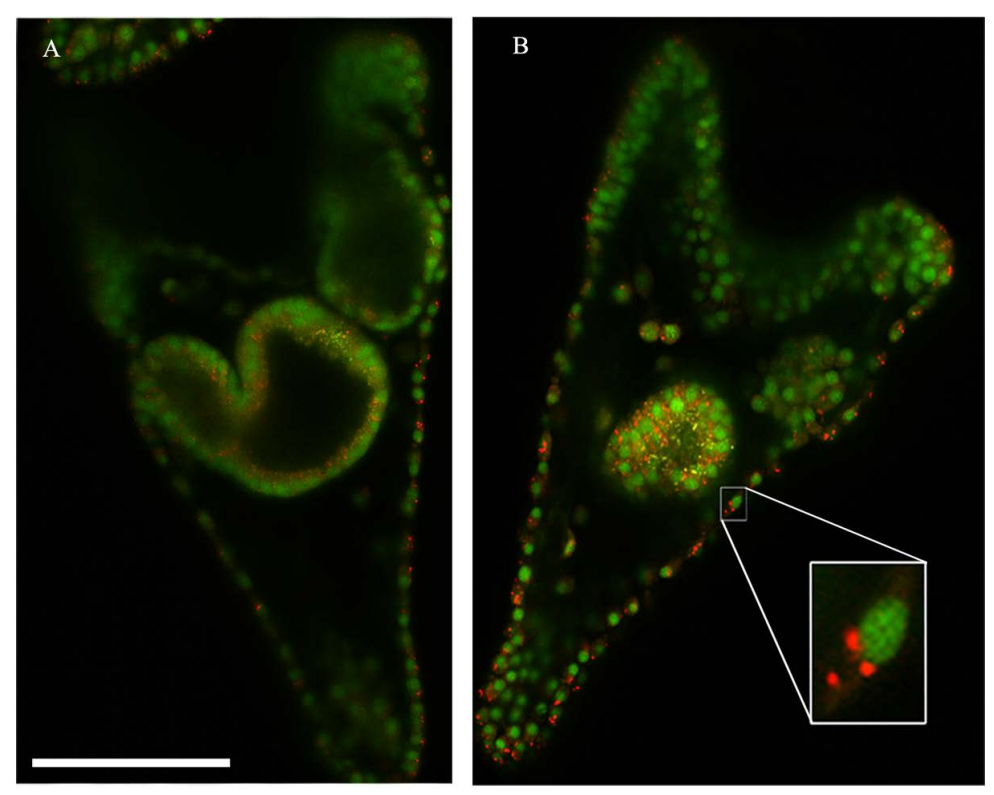

Figure 1. AO vital staining on whole-mount embryos. The images, of representative embryos, were captured by CLSM. Control embryo after $38 \mathrm{~h}$ of growth (A); Cd-treated embryo for $38 \mathrm{~h}$ (B). The box shows an enlargement of a section of (B). Bar $=50 \mu \mathrm{m}$. 
The effects of heavy metals on marine invertebrates have been studied, examining accumulation, embryonic development perturbation, expression of metallothioneins, stress protein induction, apoptosis and others pathways.

Most marine invertebrates accumulate heavy metals mainly from seawater and/or diet. Mollusks, crustaceans and other marine invertebrates are known to accumulate high levels of heavy metals in their tissues and yet survive in polluted environments; thus, their peculiar position in the marine trophic chain, where pelagic larvae are part of the diet of several planktonic and benthic organisms (bio-magnification), increases the interest of many researchers. Trace essential/borderlinemetals are of environmental interest both as limiting nutrients (e.g. Fe, Zn, $\mathrm{Mn}, \mathrm{Cu}, \mathrm{Co}$, and $\mathrm{Ni}$ ), playing important roles in metal-requiring and metal-activated enzyme systems, and as toxicants when present at high concentrations. On the contrary, non-essential heavy metals (e.g. Cd, $\mathrm{Hg}, \mathrm{Ag}$ and $\mathrm{Pb}$ ) are toxic for living organisms even at low concentrations.

Cyto-protective response against stress induced by metals can vary greatly among different tissues and may result in their differential sensitivity to metal exposure, especially for non-essential metals. Many studies have shown that, in adult organisms, metal accumulation was particularly marked in specific tissues. In all examined species, heavy metals accumulated in a dose/time-dependent manner.

Considering various sources of marine pollution, monitoring the health state of the sea is essential to identify reliable markers and bioindicators highly sensitive to environmental changes.

Among the benthonic organisms, echinoderms represent a simple and significant model system to test how specific metals can simultaneously affect development and putative mechanisms of defense and/or cell death. However further studies are needed to investigate this topic, particularly in relation to the pollutants reported in this review.

The purpose of the summary of data presented here is not to review all of the work done over the years in the field by many authors, but rather to focus on a few arguments with the intent of re-examining some ideas and concepts.

\section{Acknowledgements}

We thank Dr. C. Luparello and Dr. C. Martino for critical revision of the manuscript. This work was supported by FFR 2012/13 of Palermo University to M. C. Roccheri.

\section{References}

[1] Singh, V.P. (2005) Metal Toxicity and Tolerance in Plants and Animals. Sarup \& Sons, New Delhi, 1-328.

[2] Fraústo da Silva, J.J.R. and Williams, R.J.P. (1993) The Biological Chemistry of the Elements: The Inorganic Chemistry of Life. Clarendon Press, Oxford, 1-561.

[3] Tamás, M.J. and Martinoia, E. (2005) Molecular Biology of Metal Homeostasis and Detoxification: From Microbes to Man. Springer Verlag, Heidelberg, 1-506.

[4] Scheifler, R., Coeurdassier, M., Morilhat, C., Bernard, N., Faivre, B., Flicoteaux, P., et al. (2006) Lead Concentrations in Feathers and Blood of Common Blackbirds (Turdusmerula) and in Earthworms Inhabiting Unpolluted and Moderately Polluted Urban Areas. Science of the Total Environment, 371, 197-205. http://dx.doi.org/10.1016/j.scitotenv.2006.09.011

[5] Chapman, P.M., Allen, H.E. and Z’Graggen, M.N. (1996) Evaluation of Bioaccumulation Factors in Regulating Metals. Environmental Science and Technology Journal, 30, 448A-452A. http://dx.doi.org/10.1021/es962436d

[6] Thirumoorthy, N., Shyam Sunder, A., Manisenthil Kumar, K., Senthil Kumar, M., Ganesh, G. and Chatterjee, M. (2011) A Review of Metallothionein Isoforms and Their Role in Pathophysiology. World Journal of Surgical Oncology, 20, 1-7.

[7] Reidel, G.F., Abbe, G.R. and Sanders, J.G. (1995) Silver and Copper Accumulation in Two Estuarine Bivalves, the Eastern Oyster (Crassostrea virginica) and the Hooked Mussel (Ischadiumrearrum). Estuaries, 18, 445-455. http://dx.doi.org/10.2307/1352363

[8] Bryan, G.W. and Langston, W.J. (1991) Bioavailability, Accumulation and Effects of Heavy Metals in Sediments with Special Reference to United Kingdom Estuaries: A Review. Environmental Pollution, 76, 89-131. http://dx.doi.org/10.1016/0269-7491(92)90099-V

[9] Dallinger, E. and Rainbow, P.S. (1992) Ecotoxicology of Metals in Invertebrates. Lewis, Boca Raton, 1-217.

[10] Rainbow, P.S. (2002) Trace Metal Concentrations in Aquatic Invertebrates: Why and So What? Environmental Pollu- 
tion, 120, 497-507. http://dx.doi.org/10.1016/S0269-7491(02)00238-5

[11] Kim, B.M., Rhee, J.S., Jeong, C.B., Seo, J.S., Park, G.S., Lee, Y.M. and Lee, J.S. (2014) Heavy Metals Induce Oxidative Stress and Trigger Oxidative Stress-Mediated Heat Shock Protein (hsp) Modulation in the Intertidal Copepod Tigriopus japonicus. Comparative Biochemistry and Physiology Part C: Toxicology \& Pharmacology, 66, 65-74. http://dx.doi.org/10.1016/j.cbpc.2014.07.005

[12] Tamás, M.J., Sharma, S.K., Ibstedt, S., Jacobson, T. and Christen, P. (2014) Heavy Metals and Metalloids as a Cause for Protein Misfolding and Aggregation. Biomolecules, 4, 252-267. http://dx.doi.org/10.3390/biom4010252

[13] Graeme, K.A. and Pollack, C.V. (1998) Heavy Metal Toxicity, Part I: Arsenic and Mercury. The Journal of Emergency Medicine, 16, 45-56. http://dx.doi.org/10.1016/S0736-4679(97)00241-2

[14] Schiff, K.C. (2000) Sediment Chemistry on the Mainland Shelf of the Southern California Bight. Marine Pollution Bulletin, 40, 268-270. http://dx.doi.org/10.1016/S0025-326X(99)00216-7

[15] Harada, M., Nakanishi, J., Konuma, S., Ohno, K., Kimura, T., Yamaguchi, H., et al. (1998) The Present Mercury Contents of Scalp Hair and Clinical Symptoms in Inhabitants of the Minamata Area. Environmental Research, 77, 160-164. http://dx.doi.org/10.1006/enrs.1998.3837

[16] Liu, X., Zhang, L., You, L., Yu, J., Zhao, J., Li, L., et al. (2011) Differential Toxicological Effects Induced by Mercury in Gills from Three Pedigrees of Manila Clam Ruditapes philippinarum by NMR-Based Metabolomics. Ecotoxicology, 20, 177-186. http://dx.doi.org/10.1007/s10646-010-0569-X

[17] Longo, G., Trovato, M., Mazzei, V., Ferrante, M. and Conti, G.O. (2013) Ligia italica (Isopoda, Oniscidea) as Bioindicator of Mercury Pollution of Marine Rocky Coasts. PLoS ONE, 8, e58548. http://dx.doi.org/10.1371/journal.pone.0058548

[18] Singaram, G., Harikrishnan, T., Chen, F.Y., Bo, J. and Giesy, J.P. (2013) Modulation of Immune-Associated Parameters and Antioxidant Responses in the Crab (Scylla serrata) Exposed to Mercury. Chemosphere, 90, 917-928. http://dx.doi.org/10.1016/j.chemosphere.2012.06.031

[19] Bosnjak, I., Uhlinger, K.R., Heim, W., Smital, T., Franekić-Colić, J., Coale, K., et al. (2009) Multidrug Efflux Transporters Limit Accumulation of Inorganic, but Not Organic, Mercury in Sea Urchin Embryos. Environmental Science \& Technology, 43, 8374-8380. http://dx.doi.org/10.1021/es901677r

[20] Shirneshan, G., Bakhtiari, A.R., Kazemi, A., Mohamadi, M. and Kheirabadi, N. (2012) Oyster Saccostrea cucullata as a Biomonitor for $\mathrm{Hg}$ Contamination and the Risk to Humans on the Coast of Qeshm Island, Persian Gulf, Iran. Bulletin of Environmental Contamination and Toxicology, 88, 962-966. http://dx.doi.org/10.1007/s00128-012-0607-X

[21] Zhang, Q.H., Huang, L., Zhang, Y., Ke, C.H. and Huang, H.Q. (2013) Proteomic Approach for Identifying Gonad Differential Proteins in the Oyster (Crassostrea angulata) Following Food-Chain Contamination with $\mathrm{HgCl}_{2}$. Journal of Proteomics, 94, 37-53. http://dx.doi.org/10.1016/j.jprot.2013.08.018

[22] Jarup, L., Berglund, M., Elinder, C.G., Nordberg, G. and Vahter, M. (1998) Health Effects of Cadmium Exposure a Review of the Literature and a Risk Estimate. Scandinavian Journal of Work, Environment \& Health, 24, 1-51.

[23] Kingsley, B.S. and Frazier, J.M. (1979) Cadmium Transport in Isolated Perfused Rat Liver: Zinc-Cadmium Competition. American Journal of Physiology, 236, 139-143.

[24] Foulkes, E.C. (2000) Transport of Toxic Heavy Metals across Cell Membranes. Proceedings of the Society for Experimental Biology and Medicine, 223, 234-240. http://dx.doi.org/10.1046/j.1525-1373.2000.22334.x

[25] De Lisle, P.F. and Roberts Jr., M.H. (1988) The Effect of Salinity on Cadmium Toxicity to the Estuarine Mysid (Mysidopsis bahia): Role of Chemical Speciation. Aquatic Toxicology, 12, 357-370. http://dx.doi.org/10.1016/0166-445X(88)90062-8

[26] Koizumi, T. and Li, Z.G.J. (1992) Role of Oxidative Stress in Single-Dose, Cadmium-Induced Testicular Cancer. Toxicology and Environmental Health, 37, 25-36. http://dx.doi.org/10.1080/15287399209531654

[27] Waalkes, M.P. and Rehm, S. (1998) Lack of Carcinogenicity of Cadmium Chloride in Female Syrian hamsters. Toxicology, 3,173-178. http://dx.doi.org/10.1016/S0300-483X(98)00012-2

[28] Rana, S.V. (2008) Metals and Apoptosis: Recent Developments. Journal of Trace Elements in Medicine and Biology, 22, 262-284. http://dx.doi.org/10.1016/j.jtemb.2008.08.002

[29] Sokolova, I.M., Evans, S. and Hughes, F.M. (2004) Cadmium-Induced Apoptosis in Oyster Hemocytes Involves Disturbance of Cellular Energy Balance but No Mitochondrial Permeability Transition. The Journal of Experimental Biology, 207, 3369-3380. http://dx.doi.org/10.1242/jeb.01152

[30] Dubois, M. and Hare, L. (2009) Subcellular Distribution of Cadmium in Two Aquatic Invertebrates: Change over Time and Relationship to Cd Assimilation and Loss by a Predatory Insect. Environmental Science \& Technology, 15, 356361. http://dx.doi.org/10.1021/es801406r

[31] Müller, W.E.G., Batel, R., Lacorn, M., Steinhart, H., Simat, T., Lauenroth, S., et al. (1998) Accumulation of Cadmium 
and Zinc in the Marine Sponge Suberites domuncula and Its Potential Consequences on Single-Strand Breaks and on Expression of Heat-Shock Protein: A Natural Field Study. Marine Ecology Progress Series, 167, 127-135. http://dx.doi.org/10.3354/meps167127

[32] Cebrian, E. and Uriz, M.J. (2007) Do Heavy Metals Play an Active Role in Sponge Cell Behavior in the Absence of Calcium? Consequences in Larval Settlement. Journal of Experimental Marine Biology and Ecology, 346, 60-65. http://dx.doi.org/10.1016/j.jembe.2007.02.010

[33] Viarengo, A., Arena, N., Canesi, L., Alia, F.A. and Orunes, M. (1994) Structural and Biochemical Alteration in the Gills of Copper-Exposed Mussels. In: Renzoni, A., Mattei, N., Lari, L. and Fossi, M.C., Eds., Contaminants in the Environment: A Multidisciplinary Assessment of Risk to Man and Other Organism, CRC Press, Boca Raton, 135-144.

[34] Nigro, M., Regoli, F., Rocchi, R. and Orlando, E. (1997) Heavy Metals in Antarctic Molluscs. In: Battaglia, B., Valencia, J. and Walton, D.W.H., Eds., Antarctic Communities: Species, Structure and Survival, Cambridge University Press, Cambridge, 409-412.

[35] Podgurskaya, O.V. and Kavun V.Y. (2006) Cadmium Concentration and Subcellular Distribution in Organs of the Mussel Crenomytilus grayanus from Upwelling Regions of Okhotsk Sea and Sea of Japan. Archives of Environmental Contamination and Toxicology, 51, 567-572. http://dx.doi.org/10.1007/s00244-005-0151-3

[36] Rodrigues, E., da Silva Santos, M.R., Rodrigues Jr., E., Gannabathula, S.V. and Lavrado, H.P. (2009) Arginine Metabolism of the Antarctic Bivalve Laternula elliptica (King \& Broderip, 1831): An Ecophysiological Approach. Polar Biology, 32, 691-702. http://dx.doi.org/10.1007/s00300-008-0574-1

[37] Roccheri, M.C. and Matranga, V. (2010) Cellular, Biochemical and Molecular Effects of Cadmium on Marine Invertebrates: Focus on Paracentrotus lividus Sea Urchin Development. In: Reini, G.P., Ed., Cadmium in the Environment, Nova Science Publishers Inc., New York, 337-366.

[38] Chiarelli, R., Agnello, M. and Roccheri, M.C. (2011) Sea Urchin Embryos as a Model System for Studying Autophagy Induced by Cadmium Stress. Autophagy, 7, 1028-1034. http://dx.doi.org/10.4161/auto.7.9.16450

[39] Kaur, S., Kamli, M.R. and Ali, A. (2011) Role of Arsenic and Its Resistance in Nature. Canadian Journal of Microbiology, 57, 769-774. http://dx.doi.org/10.1139/w11-062

[40] Mayer, D.R., Kosmus, W., Pogglitsch, H., Mayer, D. and Beyer, W. (1993) Essential Trace Elements in Humans. Serum Arsenic Concentrations in Hemodialysis Patients in Comparison to Healthy Controls. Biological Trace Element Research, 37, 27-38. http://dx.doi.org/10.1007/bf02789399

[41] Sloth, J.J., Larsen, E.H. and Julshamn, K. (2005) Report on Three Aliphatic Dimethylarsinoyl Compounds as Common Minor Constituents in Marine Samples. An Investigation Using High-Performance Liquid Chromatography/Inductively Coupled Plasma Mass Spectrometry and Electrospray Ionisation Tandem Mass Spectrometry. Rapid Communications in Mass Spectrometry, 19, 227-235. http://dx.doi.org/10.1002/rcm.1770

[42] Hong, S., Khim, J.S., Park, J., Son, H.S., Choi, S.D., Choi, K., et al. (2014) Species- and Tissue-Specific Bioaccumulation of Arsenicals in Various Aquatic Organisms from a Highly Industrialized Area in the Pohang City, Korea. Environmental Pollution, 192, 27-35. http://dx.doi.org/10.1016/j.envpol.2014.05.004

[43] Wu, X., Gao, M., Wang, L., Luo, Y., Bi, R., Li, L., et al. (2014) The Arsenic Content in Marketed Seafood and Associated Health Risks for the Residents of Shandong, China. Ecotoxicology and Environmental Safety, 102, 168-173. http://dx.doi.org/10.1016/j.ecoenv.2014.01.028

[44] Pagano, G., Esposito, A., Bove, P., de Angelis, M., Rota, A., Vamvakinos, E., et al. (1982) Arsenic-Induced Developmental Defects and Mitotic Abnormalities in Sea-Urchin Development. Mutation Research, 104, 351-354. http://dx.doi.org/10.1016/0165-7992(82)90168-3

[45] Gaion, A., Scuderi, A., Pellegrini, D. and Sartori, D. (2013) Arsenic Exposure Affects Embryo Development of Sea Urchin, Paracentrotus lividus (Lamarck, 1816). Bulletin of Environmental Contamination and Toxicology, 91, 565-570. http://dx.doi.org/10.1007/s00128-013-1098-0

[46] Natale, G., Basso, N. and Ronco, A. (2000) Effect of Cr (VI) on Early Life Stages of Three Species of Hylid Frogs (Amphibia, Anura) from South America. Environmental Toxicology, 15, 509-512. http://dx.doi.org/10.1002/1522-7278(2000)15:5<509::AID-TOX21>3.0.CO,2-S

[47] Urrutia, C., Rudolph, A., Lermanda, M.P. and Ahumada, R. (2008) Assessment of EDTA in Chromium (III-VI) Toxicity on Marine Intertidal Crab (Petrolisthes laevigatus). Bulletin of Environmental Contamination and Toxicology, 80, 526-528. http://dx.doi.org/10.1007/s00128-007-9310-8

[48] Ciacci, C., Barmo, C., Gallo, G., Maisano, M., Cappello, T., D’Agata, A., et al. (2012) Effects of Sublethal, Environmentally Relevant Concentrations of Hexavalent Chromium in the Gills of Mytilus galloprovincialis. Aquatic Toxicology, 120-121, 109-118. http://dx.doi.org/10.1016/j.aquatox.2012.04.015

[49] Ciacci, C., Barmo, C., Fabbri, R., Canonico, B., Gallo, G. and Canesi, L. (2011) Immunomodulation in Mytilus galloprovincialis by Non-Toxic Doses of Hexavalent Chromium. Fish \& Shellfish Immunology, 31, 1026-1033. 
http://dx.doi.org/10.1016/j.fsi.2011.09.002

[50] Emmanouil, C., Sheehan, T.M. and Chipman, J.K. (2007) Macromolecule Oxidation and DNA Repair in Mussel (Mytilus edulis L.) Gill Following Exposure to Cd and Cr(VI). Aquatic Toxicology, 82, 27-35. http://dx.doi.org/10.1016/j.aquatox.2007.01.009

[51] Baumann, Z. and Fisher, N.S. (2011) Modeling Metal Bioaccumulation in a Deposit-Feeding Polychaete from Labile Sediment Fractions and from Pore Water. Science of the Total Environment, 409, 2607-2615. http://dx.doi.org/10.1016/j.scitotenv.2011.03.009

[52] Barmo, C., Ciacci, C., Fabbri, R., Olivieri, S., Bianchi, N., Gallo, G. and Canesi, L. (2011) Pleiotropic Effects of Hexavalent Chromium (CrVI) in Mytilus galloprovincialis Digestive Gland. Chemosphere, 83, 1087-1095.

[53] Tan, Q.G., Ke, C. and Wang, W.X. (2013) Rapid Assessments of Metal Bioavailability in Marine Sediments Using Coelomic Fluid of Sipunculan Worms. Environmental Science and Technology, 47, 7499-7505.

[54] Bellas, J., Vázquez, E. and Beiras, R. (2001) Toxicity of Hg, Cu, Cd, and Cr on Early Developmental Stages of Ciona intestinalis (Chordata, Ascidiacea) with Potential Application in Marine Water Quality Assessment. Water Research, 35, 2905-2912. http://dx.doi.org/10.1016/S0043-1354(01)00004-5

[55] Peter, A.L. and Viraraghavan, T. (2005) Thallium: A Review of Public Health and Environmental Concerns. Environment International, 31, 493-501. http://dx.doi.org/10.1016/j.envint.2004.09.003

[56] Kazantzis, G. (2000) Thallium in the Environment and Health Effects. Environmental Geochemistry and Health, 22, 275-280. http://dx.doi.org/10.1023/A:1006791514080

[57] Couture, P., Fortin, C., Hare, L., Lapointe, D. and Danaè, P. (2011) Critical Review of Thallium in Aquatic Ecosystems. Research Report No R-1272, 1-36.

[58] Zitko, V. and Carson, W.V. (1975) Accumulation of Thallium in Clams and Mussels. Bulletin of Environmental Contamination \& Toxicology, 14, 530-533.

[59] Turner, A., Turner, D. and Braungardt, C. (2013) Biomonitoring of Thallium Availability in Two Estuaries of Southwest England. Marine Pollution Bulletin, 69, 172-177. http://dx.doi.org/10.1016/j.marpolbul.2013.01.030

[60] Nava-Ruiz, C., Méndez-Armenta, M. and Ríos, C. (2012) Lead Neurotoxicity: Effects on Brain Nitric Oxide Synthase. Journal of Molecular Histology, 43, 553-563. http://dx.doi.org/10.1007/s10735-012-9414-2

[61] Mansoori, A., Nabavi, S.M.B., Parsa, Y., Nabavi, S.N. and Ashrafi, M.G. (2013) The Level of Cd, Hg, Mn and Pb in Sediment and Invertebrate from North of the Persian Gulf. World Applied Sciences Journal, 28, 1048-1050.

[62] Strižak, Z., Ivanković, D., Pröfrock, D., Helmholz, H., Cindrić, A.M., Erk, M., et al. (2014) Characterization of the Cytosolic Distribution of Priority Pollutant Metals and Metalloids in the Digestive Gland Cytosol of Marine Mussels: Seasonal and Spatial Variability. Science of the Total Environment, 470-471, 159-170. http://dx.doi.org/10.1016/j.scitotenv.2013.09.051

[63] Geraci, F., Pinsino, A., Turturici, G., Savona, R., Giudice, G. and Sconzo, G. (2004) Nickel, Lead, and Cadmium Induce Differential Cellular Responses in Sea Urchin Embryos by Activating the Synthesis of Different HSP70s. Biochemical and Biophysical Research Communications, 322, 873-877. http://dx.doi.org/10.1016/j.bbrc.2004.08.005

[64] Tellis, M.S., Lauer, M.M., Nadella, S., Bianchini, A. and Wood, C.M. (2014) Sublethal Mechanisms of Pb and Zn Toxicity to the Purple Sea Urchin (Strongylocentrotus purpuratus) during Early Development. Aquatic Toxicology, 146, 220-229. http://dx.doi.org/10.1016/j.aquatox.2013.11.004

[65] Hariharan, G., Purvaja, R. and Ramesh, R. (2014) Toxic Effects of Lead on Biochemical and Histological Alterations in Green Mussel (Perna viridis) Induced by Environmentally Relevant Concentrations. Journal of Toxicology and Environmental Health, Part A, 77, 246-260. http://dx.doi.org/10.1080/15287394.2013.861777

[66] Russo, R., Bonaventura, R., Zito, F., Schröder, H.C., Müller, I., Müller, W.E., et al. (2003) Stress to Cadmium Monitored by Metallothionein Gene Induction in Paracentrotus lividus Embryos. Cell Stress Chaperones, 8, 232-241. http://dx.doi.org/10.1379/1466-1268(2003)008<0232:STCMBM>2.0.CO,2

[67] Matranga, V., Zito, F., Costa, C., Bonaventura, R., Giarrusso, S. and Celi, F. (2010) Embryonic Development and Skeletogenic Gene Expression Affected by X-Rays in the Mediterranean Sea Urchin Paracentrotus lividus. Ecotoxicology, 19, 530-537. http://dx.doi.org/10.1007/s10646-009-0444-9

[68] Vacquier, V.D. (2011) Laboratory on Sea Urchin Fertilization. Molecular Reproduction and Development, 78, $553-564$. http://dx.doi.org/10.1002/mrd.21360

[69] Roccheri, M.C., Agnello, M., Bonaventura, R. and Matranga, V. (2004) Cadmium Induces the Expression of Specific Stress Proteins in Sea Urchin Embryos. Biochemical and Biophysical Research Communications, 321, 80-87. http://dx.doi.org/10.1016/j.bbrc.2004.06.108

[70] Agnello, M., Filosto, S., Scudiero, R., Rinaldi, A.M. and Roccheri, M.C. (2007) Cadmium Induces an Apoptotic Response in Sea Urchin Embryos. Cell Stress Chaperones, 12, 44-50. http://dx.doi.org/10.1379/CSC-229R.1 
[71] Hamdoun, A. and Epel, D. (2007) Embryo Stability and Vulnerability in an Always Changing World. Proceedings of the National Academy of Sciences of the United States of America, 104, 1745-1750. http://dx.doi.org/10.1073/pnas.0610108104

[72] Filosto, S., Roccheri, M.C., Bonaventura, R. and Matranga, V. (2008) Environmentally Relevant Cadmium Concentrations Affect Development and Induce Apoptosis of Paracentrotus lividus Larvae Cultured in Vitro. Cell Biology and Toxicology, 24, 603-610. http://dx.doi.org/10.1007/s10565-008-9066-x

[73] Agnello, M. and Roccheri, M.C. (2010) Apoptosis: Focus on Sea Urchin Development. Apoptosis, 15, $322-330$. http://dx.doi.org/10.1007/s10495-009-0420-0

[74] Chiarelli, R., Agnello, M., Bosco, L. and Roccheri, M.C. (2014) Sea Urchin Embryos Exposed to Cadmium as an Experimental Model for Studying the Relationship between Autophagy and Apoptosis. Marine Environmental Research, 93, 47-55. http://dx.doi.org/10.1016/j.marenvres.2013.06.001

[75] Klionsky, D.J., Abdalla, F.C., Abeliovich, H., Abraham, R.T., Acevedo-Arozena, A., Adeli, K., et al. (2012) Guidelines for the Use and Interpretation of Assays for Monitoring Autophagy. Autophagy, 8, 445-544. http://dx.doi.org/10.4161/auto.19496

[76] Chiarelli, R. and Roccheri, M.C. (2012) Heavy Metals and Metalloids as Autophagy Inducing Agents: Focus on Cadmium and Arsenic. Cells, 1, 597-616. http://dx.doi.org/10.3390/cells1030597 
Scientific Research Publishing (SCIRP) is one of the largest Open Access journal publishers. It is currently publishing more than 200 open access, online, peer-reviewed journals covering a wide range of academic disciplines. SCIRP serves the worldwide academic communities and contributes to the progress and application of science with its publication.

Other selected journals from SCIRP are listed as below. Submit your manuscript to us via either submit@scirp.org or Online Submission Portal.
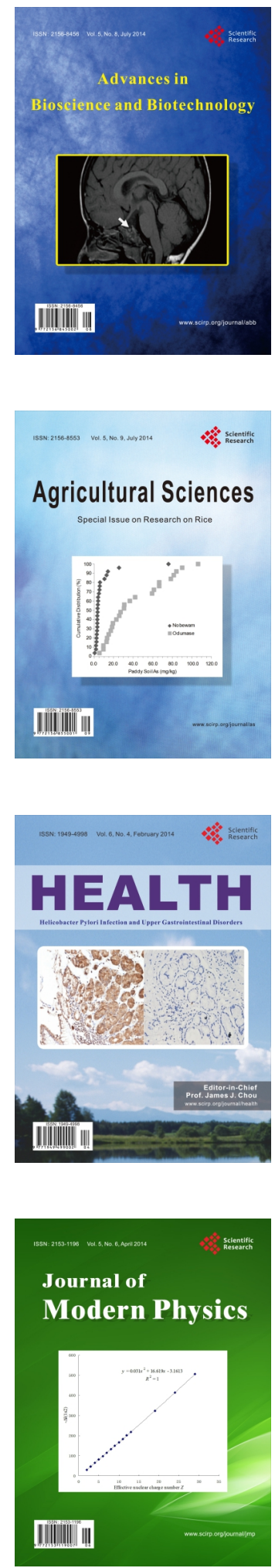
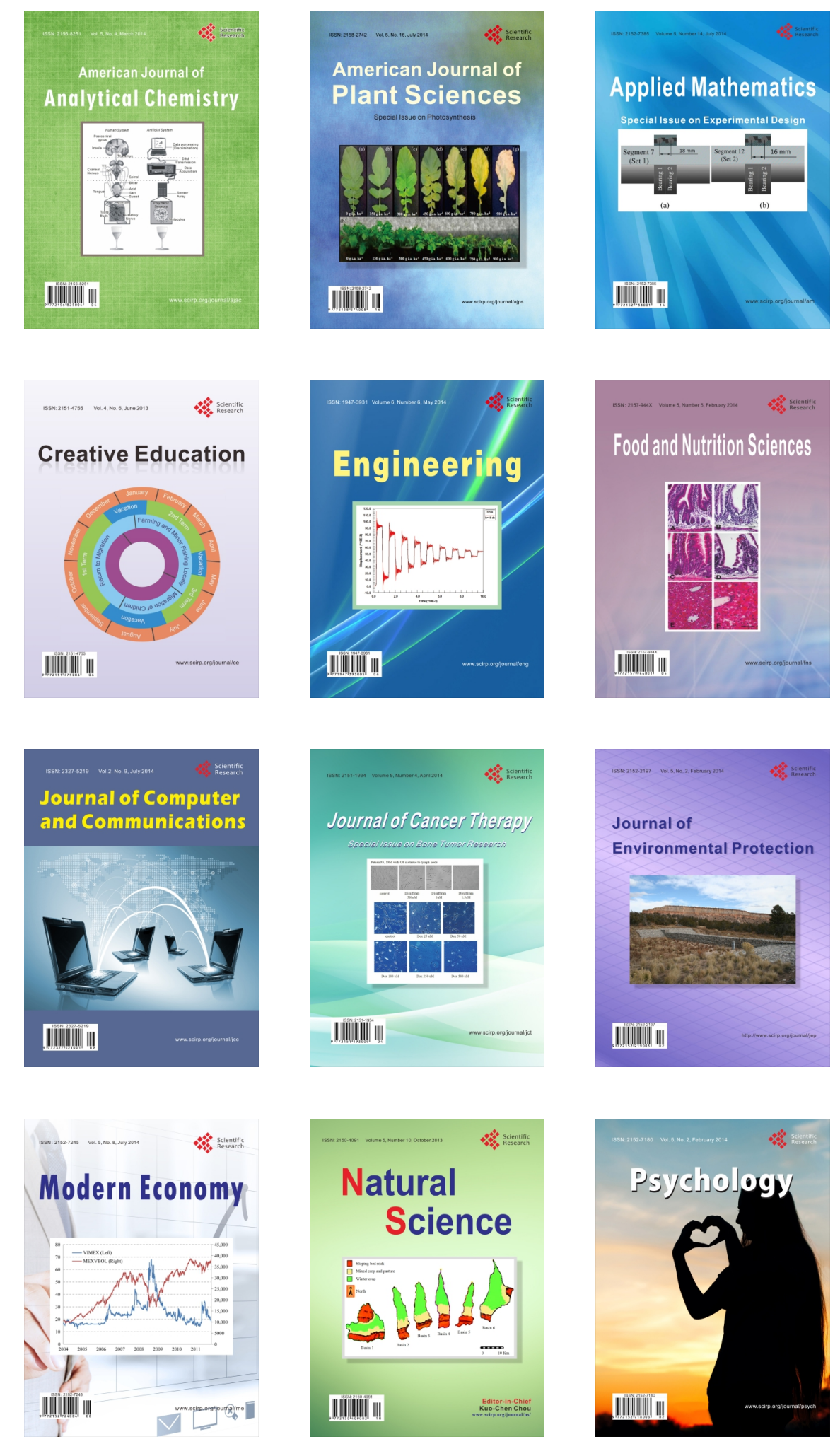